


\title{
La dramatización de las Fiestas Juninas brasileñas como estrategia didáctica en la enseñanza-aprendizaje del idioma portugués como lengua extranjera
}

\author{
A dramatization of 'Las Fiestas Juninas' as a didactic strategy in the teaching-learning \\ process of portuguese as a foreign language \\ Melina Do Rego Brito ${ }^{1}$ \\ Recibido: 27/9/2016 / Aprobado:1/11/2016
}

Resumen

\begin{abstract}
El presente artículo aborda el empleo de las Fiestas Juninas (una festividad cultural típica de Brasil) como estrategia didáctica desarrollada en el aprendizaje del idioma portugués como lengua extranjera. Esta fue realizada en el curso de Portugués Intensivo en la Sede de Occidente de la Universidad de Costa Rica, cuyo objetivo fue desarrollar la competencia intercultural en el estudiantado a la hora de comunicarse y expresarse en un idioma extranjero. Se utilizó un cuestionario para determinar los resultados de la experiencia, entre los cuales se generó: un aumento en la motivación, participación, creatividad, aprendizaje colaborativo y comprensión de la cultura brasileña.
\end{abstract}

Palabras clave: dramatización, interculturalidad, Fiestas Juninas, enseñanza-aprendizaje, portugués como lengua extranjera.

Abstract

This article focuses on implementing 'Las Fiestas Juninas', a cultural festivity from Brazil, as a didactic strategy in the teaching-learning process of Portuguese as a foreign language. This strategy was developed and applied in an intensive Portuguese course at Sede de Occidente, Universidad de Costa Rica. The objective was to develop the students' intercultural competency when they need to communicate and express themselves in a foreign language. An instrument was created to determine the results of the experience which showed an increase of students' motivation, participation, creativity, collaborative learning, and understanding of the Brazilian culture.

Key Words: dramatization, interculturality, Fiestas Juninas, teaching-learning, portuguese as a foreign language.

\section{Introducción}

Actualmente, uno de los grandes retos de los docentes es captar y mantener la atención y el interés de los estudiantes durante las clases y ese desafío se incrementa a medida en que el semestre avanza y se acerca a su conclusión. Cuando se está en una clase de lengua extranjera, factores como despertar la motivación, la creatividad y el entusiasmo por aprender hacen la diferencia, ya que para aprender un nuevo idioma, es necesario la interacción y participación de los actores involucrados: estudiantes y profesores.
Fue pensando en despertar un mayor interés en el curso y realizar un proceso más significativo de aprendizaje del portugués que, desde el año 2013, en la Sede de Occidente de la Universidad de Costa Rica, en las clases del idioma portugués, se desarrollaron distintas estrategias para que los estudiantes pudieran participar activamente del proceso de enseñanza-aprendizaje de esta lengua. La idea era adaptar la teoría a la práctica y convertir la clase en un escenario creativo y que ofreciera múltiples experiencias enriquecedoras

\footnotetext{
1 Magister en Educación con énfasis en Docencia. Profesora de portugués en la Sede de Occidente, Universidad de Costa Rica. Correo electrónico:mel.brito@yahoo.com.br
} 
y de la vida real. Este artículo expone una de estas experiencias docentes realizadas y que enriqueció no solamente el curso de portugués con nuevas estrategias, sino que han despertado el desarrollo de habilidades orales, participación, colaboración, creatividad, motivación e innovación en los estudiantes.

\section{El surgimiento de una idea}

Al final de cada semestre los estudiantes se encuentran cansados y con muchos trabajos finales, exámenes y tareas por realizar, lo que implica un grado de estrés muy grande y un gran esfuerzo por parte de todos. El curso de portugués también presenta esta situación, ya que al final del semestre, además del examen final escrito y oral, los estudiantes tienen que presentar una exposición oral final, donde deben referirse acerca de determinado tema establecido anteriormente y que se refiere a la historia, geografía o cultura brasileña, ya que lo que se quiere lograr es que conozcan y aprendan algo más sobre el país del idioma que están estudiando, en este caso, de Brasil.

Con el objetivo de buscar una actividad para motivar más a los estudiantes en las exposiciones finales, generar un mayor interés por parte de ellos y crear un aprendizaje más significativo, surgió la idea de sustituir la exposición oral teórica y convertirla en una actividad práctica, lúdica, dinámica, creativa $\mathrm{y}$, de ese modo, lograr que los estudiantes pudieran sentirse más a gusto con el idioma y que pudieran expresarse con más naturalidad y fluidez. Con base en lo anterior, se desarrolló una dramatización, en forma de comedia, que abordara la cultura brasileña, de modo que se pudiera percibir y vivenciar de forma práctica una festividad muy celebrada e importante en Brasil: las Fiestas Juninas.

\section{Un recorrido sobre las Fiestas Juninas en Brasil}

“ Olha pro céu, meu amor,

Vê como ele está lindo,

Olha praquele balão multicor,

Como no céu vai sumindo.

Foi numa noite igual a esta

Que tu me deste o coração,

O céu estava assim em festa,

Pois era noite de São João..."

(Gonzaga, L. y Fernandes, J., 2003: 42)

Las Fiestas Juninas fueron traídas a Brasil en el siglo XIX por los padres jesuitas portugueses, como el fraile Fernão Cardim (1584) y su aceptación fue inmediata en el país, por el contenido estético de las hogueras y fuegos de artificio (Chianca, 2007). Las fiestas ocurren en el solsticio de invierno, cuando es verano en Europa y fueron ampliamente estudiadas por autores como Mannhardt, Frazer e Van Gennep, debido a su gran proyección popular, en el ámbito de los trabajos rurales, originarios de actos religiosos, bailes de rueda, fiestas de comer y beber, en homenaje a los dioses de la fertilidad, propagación y vitalidad vegetal (Cascudo, 2012). Para Cascudo, folclorista e historiador brasileño, los portugueses además de traerla, la adaptaron en Brasil y tanto indígenas como africanos se identificaron inmediatamente al culto acogedor, fácil y que involucraba a todos (Cascudo, 2012).

Según Abreu (2003), los mejores relatos sobre las Fiestas Juninas fueron escritos en el final del siglo XIX por Mello Moraes Filho, historiador brasileño, quien describía las fiestas que acontecían en mediados de este siglo y que incluían a San Antonio y a San Pedro; se caracterizaban por el entusiasmo tanto en las áreas urbanas como rurales de Río de Janeiro. Además de la preparación de las hogueras, los juegos, los bailes y las comidas preparadas con maíz, las supersticiones eran el punto alto de estas fiestas, entre las principales se pueden citar: se creía que las brasas de las hogueras eran bendecidas, que el baño en el día de San Juan en los primeros rayos de sol poseía propiedades milagrosas, que las muchachas solteras podrían 
saber con quiénes se iban a casar e incluso muchos acreditaban que San Juan podría bajar a la Tierra y todo quedaría en llamas, y así, para evitar esa tragedia, se cantaba una cantiga alrededor de las hogueras (Abreu, 2003).

En Brasil, las Fiestas Juninas son celebradas en el mes de junio y se realizan en homenaje a tres santos de la iglesia católica: San Juan (día 24 de junio), San Antonio (día 13 de junio) y San Pedro (día 29 de junio). Su gran éxito consiste en que son fiestas muy familiares, donde los amigos y vecinos se reúnen y comparten con música, bailes, bebidas y juegos diversos. Chianca (2007: 51) la describe como: "una fiesta colectiva en la cual una comunidad estrecha su identidad a través de símbolos y prácticas que reafirman su pertenencia. La dimensión y extensión de la red social es lo que garantiza el éxito de la fiesta". El calendario festivo dedicado a los santos es marcado por momentos alternos de devoción y diversión, de acuerdo con aspectos circunstanciales como los momentos históricos y la experiencia personal de cada uno, lo que la convierte en una festividad dual e interesante.

Para Abreu (2003), actualmente, las Fiestas Juninas han perdido algunas características importantes apuntadas por Mello Moraes Filho, como supersticiones y han cambiado mucho con el paso del tiempo. Sin embargo, entre las principales actividades realizadas se pueden citar: el baile de las quadrilhas, el matrimonio caipira, la decoración con banderitas, la música caipira, los juegos inocentes y los quioscos con ventas de comidas y bebidas típicas. Estas tradiciones han pasado a ser parte de esta fiesta, entre finales del siglo XIX y las primeras décadas del siglo XX, entre tanto, aún no hay muchos estudios exactos sobre eso. Según la misma autora (Abreu, 2003), con las transformaciones de las grandes ciudades en Brasil, las Fiestas Juninas pasan a ser consideradas fiestas caipiras, los textos teatrales y literarios ganan proyección en esta época, donde se representa el personaje "caipira", "matuto" o "sertanejo" como una persona atrasada en relación con la modernidad, pero que pasa a ser muy representado durante estas festividades y se convierte en el personaje principal.
Otro ritual bastante conocido en la fiesta junina es el matrimonio junino, también denominado caipira o matuto, que trata de una obra teatral que se refiere al matrimonio de dos jóvenes del campo y que generalmente posee el siguiente guion: un muchacho joven deja a su novia embarazada y se rehúsa a casarse con ella, delante de sus padres, que son amigos entre sí, pero que pertenecen a clases sociales diferentes. En la "ceremonia" se encuentran representados las diversas autoridades civiles y religiosas de la sociedad (delegado, sacerdote, invitados). Los padres de la novia tratan de convencer al muchacho a casarse con su hija y este durante la escena trata de huir en diversas ocasiones. Al final de la boda, es cuando se realiza el baile denominado la quadrilha (Chianca, 2007).

La quadrilha es un baile bastante antiguo, resultado de bailes europeos y que llegó a Brasil durante la primera mitad del siglo XIX a Río de Janeiro, como una de las huellas de las tradiciones francesas en la cultura brasileña y en sus inicios eran realizada en bailes durante el periodo monárquico. En la segunda mitad del siglo XIX, se intensificó la creación de quadrilhas distintas de las francesas, pasaron a ser recreadas de acuerdo con nuevos ritmos musicales y coreografías (Zamith, 2007). Actualmente, la quadrilha está restringida a las festividades del ciclo junino, pero aún se identifican algunos de los mismos movimientos coreográficos practicados en los bailes del siglo XIX, que pueden tener una secuencia ensayada y ordenada por una persona, quien va marcar el baile para hombres, mujeres y parejas. Tanto el matrimonio junino como el baile de quadrilha presentan variaciones locales y regionales que van a depender de la creatividad y originalidad de los participantes involucrados en la festividad. 


\section{La importancia de conocer sobre la cultura del país del idioma que se estudia}

En la sociedad globalizada, el aprendizaje de uno o más idiomas extranjeros es una necesidad académica y laboral. Los docentes de una lengua extranjera saben que todo el proceso de enseñanza-aprendizaje de un nuevo idioma conlleva su tiempo, donde es fundamental que el estudiantado se encuentre motivado a seguirlo de forma que le sea posible alcanzar el objetivo final: hablar correctamente y comunicarse en el idioma extranjero.

Aunque las clases de idioma sean interesantes, algunas veces no se logran alcanzar satisfactoriamente todos los objetivos propuestos y por eso surge la necesidad de crear estrategias didácticas distintas, creativas e innovadoras, las cuales puedan despertar el interés y al mismo tiempo motivar a los estudiantes.

Existen muchas etapas en el aprendizaje de una lengua extranjera, que van desde aspectos gramaticales hasta expresiones idiomáticas, pero comunicarse con el otro presupone, además de todo lo anterior, acercarse a su cultura, conocerla y tener una visión más amplia del otro y del mundo. Níkleva afirma que "aprender una lengua extranjera significa aprender a comunicarse. En este sentido es un proceso de socialización que comprende el conocimiento y el uso de los papeles sociales y la identidad social de los hablantes de esa lengua" (2009, p.35). En otras palabras, además de conocer la estructura, gramática, vocabulario y expresiones de la lengua extranjera, es fundamental saber comunicarse y esto involucra una integración, una manera más integral de ver el mundo. Una de las formas de que exista esta integración, este encuentro, es a través de la cultura.

En el proceso de enseñanza-aprendizaje de una nueva lengua es importante conocer aspectos relevantes sobre las tradiciones y manifestaciones culturales del país o países hablantes del idioma. La lengua portuguesa no queda fuera de esta regla, ya que eso generaría mayores posibilidades de una mejor comunicación y una manera más efectiva y asertiva de hablar e interpretar a las personas. Esto evitaría menos confusiones, preconceptos, discriminaciones y estereotipos.

El docente de una lengua extranjera desempeña el papel fundamental de integrar al estudiantado en la cultura y no solamente en las reglas gramaticales del idioma estudiado. En este mismo sentido, autores como Benito (2002), Caballlero (1998), Níkleva(2009), Parraquett (2005), entre otros exponen y defienden la importancia de integrar la cultura al idioma. El docente debe conocer sobre diversos aspectos culturales, con el fin de construir este conocimiento con los alumnos. Además, debe generar inquietudes para que los estudiantes puedan investigar más. En este sentido, Níkleva establece que: "Los componentes culturales deben formar parte de la enseñanza y el aprendizaje de una lengua extranjera, puesto que representan un subgrupo de la competencia comunicativa, necesaria para que se efectúen con éxito las relaciones interculturales" (Níkleva, 2009, p.34). Así es posible determinar que para que sea posible una comunicación satisfactoria con otra persona, se deben conocer aspectos importantes acerca de sus tradiciones y manifestaciones culturales, eso es determinante para alcanzar una comunicación asertiva y sin preconceptos.

En el proceso de enseñanza-aprendizaje de una lengua extranjera, se hace también fundamental que el docente sea el representante de la cultura del país o países que hablan el idioma objeto de estudio, para eso necesita tener suficiente conocimiento y habilidad. Usualmente, se hace difícil que el estudiantado logre comunicarse con personas originarias del país o países que hablan la lengua estudiada, de ahí, deviene esta necesidad. Para García-Viñó y Massó Porcar (Embajada de España,2007: 9) "Cuando el alumno aprende la lengua, como lengua extranjera y su contacto con la cultura meta es, por tanto, muy limitado, el profesor asume el rol de representante cultural, asumiendo una responsabilidad que le debería hacer reflexionar seriamente sobre sus valoraciones y comentarios, tanto sobre su propia cultura como sobre la del alumno. El profesor se convierte en un modelo, 
siendo a veces la única persona de la cultura meta con la que el alumno puede interactuar".

En este sentido, el docente es una pieza fundamental a la hora de hablar y construir el conocimiento de la cultura para el estudiante que aprende el idioma extranjero y, por lo tanto, debe actuar de forma consciente y estar siempre actualizado acerca de los cambios, novedades y modificaciones ocurridas en el contexto del país o países hablantes de la lengua objeto de estudio. En el caso de Brasil, un país con una gama amplia de manifestaciones folclóricas, sería imposible aprender la lengua portuguesa sin hablar de su cultura. También es fundamental que los propios estudiantes puedan tener la curiosidad y motivación suficientes para conocer e investigar cada vez más,sobre la cultura meta, en este caso la brasileña.

\section{Una mirada sobre la competencia intercultural}

En los últimos años, se ha hablado mucho sobre la competencia intercultural en el ámbito de lenguas extranjeras. El Diccionario de términos clave de Español como Lengua Extranjera del Centro Virtual Cervantes la define como: "la habilidad del aprendiente de una segunda lengua o lengua extranjera para desenvolverse adecuada y satisfactoriamente en las situaciones de comunicación intercultural que se producen con frecuencia en la sociedad actual, caracterizada por la pluriculturalidad" (2016).

Martín (2005) realiza un amplio estudio sobre la competencia intercultural en el ámbito de lenguas extranjeras, por su parte Meyer (1991) afirma que "como parte de una amplia competencia del hablante de una lengua extranjera, identificando la habilidad de una persona de actuar de forma adecuada y flexible al enfrentarse con acciones, actitudes y expectativas de personas de otras culturas". También el autor Oliveras (2000: 38) expone que “ la capacidad de estabilizar la propia identidad en el proceso de mediación entre culturas y de ayudar a otras personas a estabilizar la suya". La competencia intercultural es un concepto complejo y amplio, el cual engloba diversas disciplinas y ciencias, como la Lingüística, Antropología, Psicología, Filosofía, Etnografía y Sociolingüística.
Para Benito (2009), el desarrollo de la competencia intercultural es diferente de aprender cultura en la clase de lengua extranjera. El enfoque intercultural contempla una interacción; considera, por lo tanto, la cultura del país objeto de estudio, como también la del país del estudiante, ya que este último mpuede comparar aspectos culturales de su propio país con los del país que está estudiando, para propiciar una actitud crítica con respeto a eso. Tal como lo afirma la autora en la cita anterior, como docentes de una lengua extranjera, es necesario considerar todo el conocimiento tenido por el estudiante de su propia realidad, para así poder tratar de entender otras. Es labos del docente prepararse dentro de la clase y fuera de esta, además de conocer acerca de la cultura, tanto del país objeto de estudio como del país donde se brinden las clases. De esta manera es posible crear un nivel más significativo de aprendizaje y que el estudiantado valore más su propia cultura y respete las culturas distintas.

Sáenz (2002) considera que el contexto de la enseñanza de idiomas, por su carácter dialógico e interactivo, es un lugar y momento ideal para el desarrollo de una competencia intercultural más compleja y de valor educativo, que implica, por parte del profesor, reconocer que todo individuo pertenece a diversas culturas, y la incorporación a la clase de aspectos como diversidad, conciencia cultural y análisis crítico.

Para Martín (2005) es importante que el docente de una lengua extranjera pretenda que los estudiantes alcancen un nivel de bilingües equilibrados, o sea, que dominen tanto la lengua materna como la extranjera de una forma igualitaria y sugiere varias metodologías posibles de aplicar en las clases, desde diálogos, experiencias e investigaciones que fomenten la participación de los estudiantes y la colaboración entre ellos. Entre las metodologías sugeridas por Martín (2005), quien plantea trabajar la competencia intercultural con un enfoque socioafectivo, se pueden citar las siguientes pautas: vivenciar una experiencia donde se manifieste la diversidad de puntos de vista de dos culturas, ya sea, real o simulada, por parte del alumno como miembro de su grupo o 
de un grupo menor dentro del grupo de clase; describir y analizar esta experiencia tanto en su transcurso, como las reacciones de los estudiantes, emociones, resoluciones de conflictos, variaciones de comportamientos, actitudes; contrastar la experiencia vivida con situaciones de la vida real; y evaluar la actividad, el grado de éxito y de aceptación entre el estudiantado.

Con base en lo anteriormente expuesto, se trazó la estrategia por seguir: se planteó la dramatización de las Fiestas Juninas como recurso didáctico para desarrollar un mejor aprendizaje en los estudiantes de portugués, además de habilidades interculturales, participativas, expresivas, de aprendizaje cooperativo, de motivación y de creatividad.

\section{Planteamiento de la estrategia: ¿para qué usar la dramatización?}

Para Aguilar López (2012), hay que establecer bien la diferencia entre teatro y dramatización, puesto que el teatro es un producto realizado con el fin de ser consumido por un público, mientras que la dramatización tiene un objetivo pedagógico, lo que implica enfatizar en todo el proceso y no solamente en el resultado final. Además, es una forma antigua de expresión del ser humano.

Usar la actuación como una herramienta en las clases de idiomas ayuda a desarrollar además el lenguaje oral y expresivo, promueve el uso del idioma extranjero, crea más confianza en los estudiantes a la hora de hablar y desarrolla el trabajo en equipo, la colaboración y la participación activa del grupo. Es decir, la actuación es una forma fundamental de motivar, de usar la creatividad y propiciar situaciones tanto reales como imaginarias dentro de la clase, que estimulan la práctica de importantes habilidades comunicativas entre el estudiantado. También en este sentido, Vicente-Yagüe y Martínez (2016: 20) establecen que "la dramatización presenta un carácter social, lúdico y cooperativo, que como instrumento pedagógico potencia al estudiante, el desarrollo de sus habilidades sociales, trabajo en equipo, fortalece su autoestima y aumenta su confianza".
Para Diez (2011), los juegos dramáticos crean situaciones que permiten a los aprendices interactuar de manera significativa. Asimismo, las improvisaciones, escenarios, y los juegos con personajes permiten a los estudiantes, además de probar y evaluar sus propias hipótesis sobre la lengua meta, usarla de forma más creativa e espontánea mediante la exposición de la competencia adquirida, la cual permite recrear situaciones de la realidad exterior del aula.

En este sentido, se desarrolló la estrategia de la dramatización aplicada a la enseñanza-aprendizaje de la lengua portuguesa; consiste en transformar el aula en un escenario de actuación inteligente en el cual los actores (docentes y estudiantes) adquieran y renueven competencias comunicativas, participativas y cooperativas (Solari,2013). Esta técnica tiene como base el aprendizaje cooperativo. Dentro de sus metas principales se apuntan "crear confianza entre los estudiantes, comunicación directa y asertiva, respeto mutuo y tolerancia, valoración mutua del trabajo, amistad, buen trato, liderazgo compartido y trabajo en equipo" (Tobón, 2005, p. 214).

Para Núñez y Navarro (2007: 238): “el drama es un medio privilegiado que desarrolla la creatividad, ya que requiere de la elaboración de nuevas situaciones y respuestas utilizando los recursos lingüísticos, corporales, musicales, gestuales, etc.. Estos mismos autores defienden la relevancia de la aplicación de la dramatización en el área de Lenguas, en lo que se refiere al aprendizaje de lenguas extranjeras, se hace fundamental la necesidad de adentrarse en la cultura, costumbres y situaciones reales de la vida cotidiana. En este proceso, la dramatización se convierte en una herramienta importante en esta área (2007: 241). 


\section{Dramatización: "Festas Juninas - arraial do grupo de português intensivo 1"}

Tanto las Fiestas Juninas como los rituales involucrados en estas festividades, como el matrimonio y el baile típico "quadrilha", son expresiones muy importantes del folclore y cultura popular de Brasil. El desarrollo de esta estrategia didáctica fue una oportunidad para que los estudiantes del curso de portugués conocieran más sobre la riqueza y diversidad de la cultura brasileña.

El objetivo general planteado de la estrategia didáctica ejecutada fue desarrollar la competencia intercultural en el estudiantado del curso de Portugués Intensivo 1 a través de la dramatización de la obra teatral "Festas Juninas: Arraial do Grupo de Português Intensivo 1 - UCR - Sede Ocidente" con el fin de lograr un aprendizaje significativo, cooperativo, creativo y una mayor motivación para expresarse oralmente en el idioma portugués. Como objetivos específicos se plantearon los siguientes: aprender y conocer acerca de las tradiciones, origen, historia, costumbres, culinaria que se encuentran presentes en estas festividades en Brasil para tener un aprendizaje más significativo; vivenciar en la práctica una importante tradición de la cultura brasileña con la finalidad de fomentar un conocimiento más amplio, contextualizado y más allá de lo teórico; crear una mayor motivación en el estudiantado a la hora de presentar las exposiciones finales para que se expresaran con mejor y con más fluidez; y fomentar en las personas que asisten al curso el trabajo en equipo y colaborativo, respeto, tolerancia, solidaridad, diálogo, creatividad e innovación a la hora de aprender un nuevo idioma.

\section{Contexto, descripción y desarrollo de la estrategia didáctica}

La estrategia fue desarrollada en el curso de Portugués Intensivo 1, en la Sede de Occidente de la Universidad de Costa Rica durante el primer semestre del año 2016. El curso es de idiomas, donde se desarrollan las habilidades de escritura, lectura, así como las de comunicación oral y auditiva, donde personas de cualquier carrera pueden matricular y llegar sin ningún conocimiento de este idioma; sin embargo, como es un curso intensivo, logran avanzar, al final, la mayoría logra desarrollarse bastante en este, si se compara el nivel de similitud con la lengua española y el nivel de conocimiento que tenían cuando ingresaron, además de que logran aplicar el portugués como herramienta en sus carreras.

El estudiantado realizó la dramatización de las Fiestas Juninas en Brasil en sustitución de los trabajos teóricos finales, de la siguiente forma:

1. En la primera parte de la actividad se realizó una exposición teórica por parte de un grupo de estudiantes, donde se logró conocer por parte del grupo, la importancia, origen, historia y tradiciones de las Fiestas Juninas.

2. En la segunda parte, se llevó a cabo una dramatización, en la cual se celebraba un matrimonio matuto, una historia cómica que relata el matrimonio entre un joven que no quería casarse con la novia. El hecho de pertenecer a clases sociales diferentes crea una cierta tensión en el ambiente, pero que al mismo tiempo genera situaciones divertidas, principalmente cuando llega la "amiga" del novio (quien supuestamente está embarazada del muchacho - esta última parte fue creada por el propio grupo, con el fin de convertirla en algo más divertido y actual). Finalmente se baila la quadrilha, que se da al final del matrimonio, como forma de celebrar el acontecimiento.

La estrategia fue desarrollada de la siguiente forma:

1. Primero se trabajó con un grupo de 36 estudiantes, entre los cuales 22 participaron directamente $y$, tal como se mencionó anteriormente, se sistituyeron las exposiciones orales teóricas por una única exposición final, combinada con la dramatización y el baile típico de la quadrilha.

2. Cuatro estudiantes desarrollaron la exposición oral, a través de una investigación de los temas más relevantes involucrados en esta festividad, entre los cuales se destacan: historia y origen, 
importancia en Brasil del evento, culinaria típica, bailes, juegos, costumbres y tradiciones. Se expusieron los temas para que el resto, que no había participado de la presentación (grupo invitado), lograra entender lo que ellos iban a realizar.

3. Los otros 18 estudiantes ensayaron la dramatización y el baile típico, con la orientación y supervisión de la profesora, durante aproximadamente dos meses y tanto los diálogos como el baile se desarrollaron de forma muy natural, clara y objetiva, a fin de que los asisntentes lograran entender y aprender más sobre la cultura brasileña.

4. Durante las dos últimas semanas, se discutió en conjunto con los miembros del grupo aspectos relevantes como la forma de expresarse, los cambios de diálogos y los aportes del estudiantado. Además, se ensayó fuera del horario de clases, tiempo durant el cual se determinaron personajes, vestuario, decoración, comida y los temas por investigara.

5. En el día de la presentación de la actividad, se realizó todo lo expuesto anteriormente y de acuerdo con la agenda previamente establecida de los detalles e informaciones. Después se llevó a cabo la exposición teórica, se mostraron los aspectos más relevantes ya citados, seguida de la dramatización y del baile típico. Al final de la actividad, que duró aproximadamente una hora, hub una merienda con un menú típico de las Fiestas Juninas, que contiene bocadillos y comidas a base de maíz.

\section{Valoración de la estrategia}

\section{Análisis de los resultados, ventajas y limitaciones}

Después de la aplicación de la estrategia, se elaboró un cuestionario impreso con preguntas cerradas dicotómicas, entre las cuales se indagaron aspectos como: motivación, importancia de la aplicación de la estrategia, participación, trabajo en equipo, conocimiento acerca de otras culturas a la hora de aprender un nuevo idioma, desarrollo de la creatividad y aprendizaje colaborativo entre los participantes.

Con el fin de valorar los resultados y el alcance de la actividad, entre las principales ventajas que arrojaron los cuestionarios se encuentra el hecho de que la estrategia logró aumentar considerablemente la motivación del grupo, ya que la totalidad de los estudiantes declararon que se sentían más motivados después de haber participado de la actividad. Un punto importante que se debe mencionar en esta parte del cuestionario es que los no participantes directos de la actividad se mostraron interesados en participar en actividades culturales futuras. Además, se logró aumentar la participación y la colaboración entre el grupo de estudiantes, se desarrolló más la creatividad, el trabajo en equipo, la confianza, amistad y el respeto entre los participantes, así como también los resultados demostraron que hubo una mejora considerable en la comprensión y el conocimiento acerca de aspectos importantes de la cultura brasileña (festividades importantes en Brasil, formas de vestir, música, vestuario típico de determinadas regiones) y del idioma portugués, como formas de hablar y de expresarse (diversidad de expresiones y estilos de lenguaje).

Después de este breve análisis acerca de los resultados obtenidos, y según las pautas establecidas para desarrollar la estrategia planteada con el fin de trabajar la competencia intercultural (Martín, 2005), se puede decir que se lograron alcanzar los objetivos propuestos, debido a que la vivencia de la experiencia generó un conocimiento más amplio y significativo acerca de la cultura brasileña, resaltó la diversidad entre dos realidades y contextos diferentes; además, ayudó a aumentar la participación, creatividad y trabajo colaborativo entre el grupo de estudiantes.

Otro aspecto importante fue crear consciencia de que a pesar de las diferencias culturales, existen puntos en común entre los pueblos; sin embargo es necesario conocer más profundamente los diversos contextos y realidades, para que se logre comprender eso. En este sentido, el docente, con su labor, debe ser capaz de colaborar en el desarrollo 
de actitudes positivas respecto a la diversidad, y al respeto mutuo frente a otras personas y culturas.

Con esta experiencia, parece pertinente lo que establecido por González, en el sentido de que se logró integrar la adquisición de la lengua extranjera con el componente cultural, de modo que el estudiantado pudiera reflexionar, comparar, analizar y crear actitudes adecuadas a fin de enfrentar a la diversidad (Embajada de España, 2007). Se debe mencionar también que se fomentó de forma positiva la motivación del grupo, ya que hubo considerable grado de aceptación de la actividad y su evaluación entre el estudiantado fue positiva. Además, se produjo un aprendizaje más práctico y por lo tanto, más real y significativo, ya que pudieron vivenciar la experiencia, durante todo el curso, tanto dentro como fuera del aula.

Finalmente, la experiencia llevó al estudiantado a reflexionar acerca de la importancia de su cultura, de sus propias festividades, a establecer comparaciones, a determinar similitudes y distinciones con su propio contexto y realidad.

Entre las principales limitaciones de la estrategia se anotan las siguientes:

1. Falta de asistencia a los ensayos por parte de algunos del grupo, ya que los ensayos se dieron, muchas veces, en horarios fuera de las clases.

2. Falta de recursos económicos para desarrollar mejor la actividad, ya que los estudiantes tuvieron que hacerse responsables por todo, desde la comida hasta el vestuario y la decoración.

3. Poco tiempo para desarrollar la estrategia, puesto que durante el semestre existen muchas obligaciones por parte del docente y los estudiantes.

A pesar de las limitaciones apuntadas anteriormente, desde la perspectiva docente, desarrollar nuevas estrategias didácticas en los cursos de idiomas es necesario y fundamental, ya que compete a cada educador tratar de encontrar los medios, recursos y soluciones para realizar mejor cada día el trabajo, con creatividad, innovación y participación de los estudiantes.
Aunque la estrategia didáctica ya se había desarrollado en otras ocasiones y con diferentes grupos, esa fue la primera vez que se logró realizar con un grupo principiante del curso de portugués y eso la hace más novedosa, creativa e innovadora, ya que presenta un desafío enorme tanto para el docente como para el grupo, debido a que el estudiantado apenas está teniendo contacto con el idioma.

\section{Consideraciones finales}

Como docentes del idioma portugués, se considera que es importante seguir planteando $\mathrm{y}$ trabajando diferentes estrategias y actividades culturales en los cursos, de modo que los estudiantes sigan motivándose a aprender cada día más. Aprender un nuevo idioma no es una tarea fácil: a pesar de ser una necesidad tanto en el nivel académico como en el laboral, se requiere de gran esfuerzo y dedicación por parte del docente y del estudiante.

Es indispensable que el estudiantado se sienta parte de lo que está aprendiendo. La cultura, por su carácter vivencial, es significativa y lograr que los alumnos participen de esta es parte fundamental del proceso de enseñanza-aprendizaje de un idioma extranjero, en este caso específico, del idioma portugués, pues aumenta su conocimiento en todos los aspectos, incluso les permite reflexionar acerca de la importancia de su propia cultura.

En el ámbito universitario, debe existir consciencia de la importante labor de preparar nuestros estudiantes tanto en el ámbito profesional, sino prepararlos de forma integral. Actividades como estas, los estimulan a que se preparen para actuar en una lengua extranjera. Además, los permiten aprender a expresarse correctamente y con mayor fluidez. La confianza en sí mismos, el trabajo en equipo y el respeto hacía la diversidad cultural son otros aspectos importantes que deben ser mencionados.

El docente actual como uno de los actores fundamentales en el proceso de enseñanzaaprendizaje es llamado a adquirir además de su intelectualidad y el conocimiento en su 
campo, habilidades artísticas de varios tipos y destrezas como la actuación y la expresión corporal, que lo colocan de nuevo en el centro del escenario educativo, con un papel al menos co-estelar" (Gutiérrez-Soto y Piedra, 2015: 195)

Vivenciar de cerca una festividad que representa parte importante de la cultura del país $\mathrm{y}$ del idiomaestudiado es fundamental para entender y asimilar mejor la lengua extranjera, además de que motiva más y fomenta el interés en conocer otros horizontes fuera de la clase, amplía el conocimiento del estudiante y su visión hacia la diversidad de la lengua y de la cultura brasileña.

Por la importancia del folclore en Brasil, traer la dramatización de una festividad como las fiestas juninas a nuestros cursos, lo enriquece de modo significativo, ya que permite valorar aspectos fundamentales en el aprendizaje de un idioma extranjero, como la idiosincrasia, historia, origen, costumbres y tradiciones, todos estos considerados importantes al de aprender una lengua extranjera. 


\section{Referencias bibliográficas}

Abreu, M. (2003). Cultura Popular, um conceito e varias histórias. Casa da Palavra: São Paulo, Brasil. Recuperado de https://goo.gl/RDMdJx

Aguilar López, M. (2012). Influencia de la dramatización en la expresión oral de discentes universitarios extranjeros y nativos. (Tesis de licenciatura). Universidad de Burgos. Recuperado de https://goo.gl/AYSSwO

Benito, A. B. G. (2002). "La cultura en la enseñanza del portugués lengua extranjera: análisis y propuestas de integración". Anuario de estudios filológicos, (25), 119-135. Recuperado de http://hispadoc.es/descarga/articulo/298587. pdf

Benito, A. B. G. (2009). La competencia intercultural y el papel del profesor de lenguas extranjeras. Actas del XIX Congreso Internacional de la Asociación para la Enseñanza del Español como Lengua Extranjera (ASELE). Cáceres, 24-27 de septiembre de 2008, 493-506. Recuperado de https://goo.gl/vIcr8s

Caballero, J. (1998). "La adquisición de conceptos culturales y el aprendizaje de la cultura". Frecuencia, 7, 3-11.

Câmara Cascudo, L. (2012). Folclore do Brasil: pesquisas e Notas. Global Editora: São Paulo, Brasil.

Centro Virtual Cervantes. (2016). Diccionario de términos clave de español como lengua extranjera. Recuperado de https://goo.gl/ $\mathrm{Ja} 0 \mathrm{tRH}$

Chianca, L. (2007). "Devoção e diversãoExpressões contemporâneas de festas e santos católicos". Revista Anthropológicas, 18, (2), 49-72. Recuperado de https://dialnet.unirioja.es/ servlet $/$ articulo? codigo $=3128413$
Diez, M. D. P. (2011). El texto dialógico como instrumento de aprendizaje en el aula de ELE. El "Recurso" del teatro como estrategia dinamizadora. Recuperado de https://goo. gl/7ZBrks

Gutiérrez-Soto, M. y Ángel Piedra, L. (2015). Docencia constructivista en la universidad : una serie de ensayos sobre experiencias en Costa Rica. Recuperado de https://goo.gl/ WmZDOZ

Embajada de España. (2007). Cuadernos de Rabat, $\mathrm{n}^{\circ}$ 19. Cultura intercultura en español lengua extranjera. Recuperado de https://goo.gl/ jwuwdB

Gonzaga, L. y Fernández, J. (2003). Música para acordeom: Tributo a Luis Gonzaga. Editorial Irmaos Vitales, Brasil. Recuperado de https:// goo.gl/fDdKIG

Gutiérrez-Soto, M. y Piedra, L.A. (2015). Docencia constructivista en la universidad: una serie de ensayos sobre experiencias en Costa Rica. Editorial Universidad de Costa Rica: San José, Costa Rica.

Martin, M.R. (2005). “De la competencia intercultural en la adquisición de una segunda lengua o lengua extranjera: conceptos, metodología y revisión de métodos". Revista Porta Linguarum, 3, 79-94. Recuperado de https://goo.gl/JmGG5d

Martínez Vidal, e. (1991). El uso de la cultura en la enseñanza de la lengua. Recuperado de https://goo.gl/Y92gXP

Meyer, M. (1991). “Developing transcultural competence: Case studies of advanced foreign language learners. Mediating languages and cultures. Clevedon". Multilingual Matters, págs. 136-159 
Níkleva, D. G. (2009). "La convivencia intercultural y su aplicación a la enseñanza de lenguas extranjeras". Ogigia: Revista electrónica de estudios hispánicos, 5, 29-40. Recuperado de https://goo.gl/VypOyL

Núñez Cubero, L. y Navarro Solano, M. (2007). La dramatización y educación. Ediciones Salamanca, España. Recuperado de https:// goo.gl/JyuYxc

Oliveras, A. (2000). Hacia la competencia intercultural en el aprendizaje de una lengua extranjera. Editorial Edinumen: España. Recuperado de https://goo.gl/DKiuZB

Paraquett, M. (2005). Multiculturalismo y aprendizaje de lenguas extranjeras. InActas del II Simposio José Carlos Lisboa de Didáctica de Español para Extranjeros. Recuperado de https://goo.gl/6n $2 \mathrm{fyU}$

Sáez, F. T. (2002). Objetivos en la enseñanza de lenguas extranjeras: De la competencia lingüística a la competencia intercultural. Actas del congreso: "Inmigración, Convivencia e Interculturalidad". Recuperado de https:// goo.gl/FtJ7Xd

Solari, D. (2016). Estrategias del arte dramático aplicadas al aprendizaje-enseñanza de la lengua portuguesa como lengua extranjera. Recuperado de https://goo.gl/ZLlPce

Tobón, S. (2005). Docencia Estratégica: Formación basada en competencias. (2a. ed.). Ecoe Ediciones: Bogotá.

Vicente-Yagüe, M.I y Martínez, M. (2016). "La dramatización musical del romancero en educación primaria para el desarrollo de la competencia social y ciudadana”. Educatio, 34 (1), 11-29. Recuperado de https://goo.gl/ xarnV7
Zamith, R.M. (2007). “A dança da quadrilha na cidade do Rio de Janeiro: sua importância na sociedade oitocentista". Textos excolhidos de cultura e arte populares, 4, (1), 113-132. Recuperado de http://www.tecap.uerj.br/pdf/ v4/zamith.pdf 
Anexo
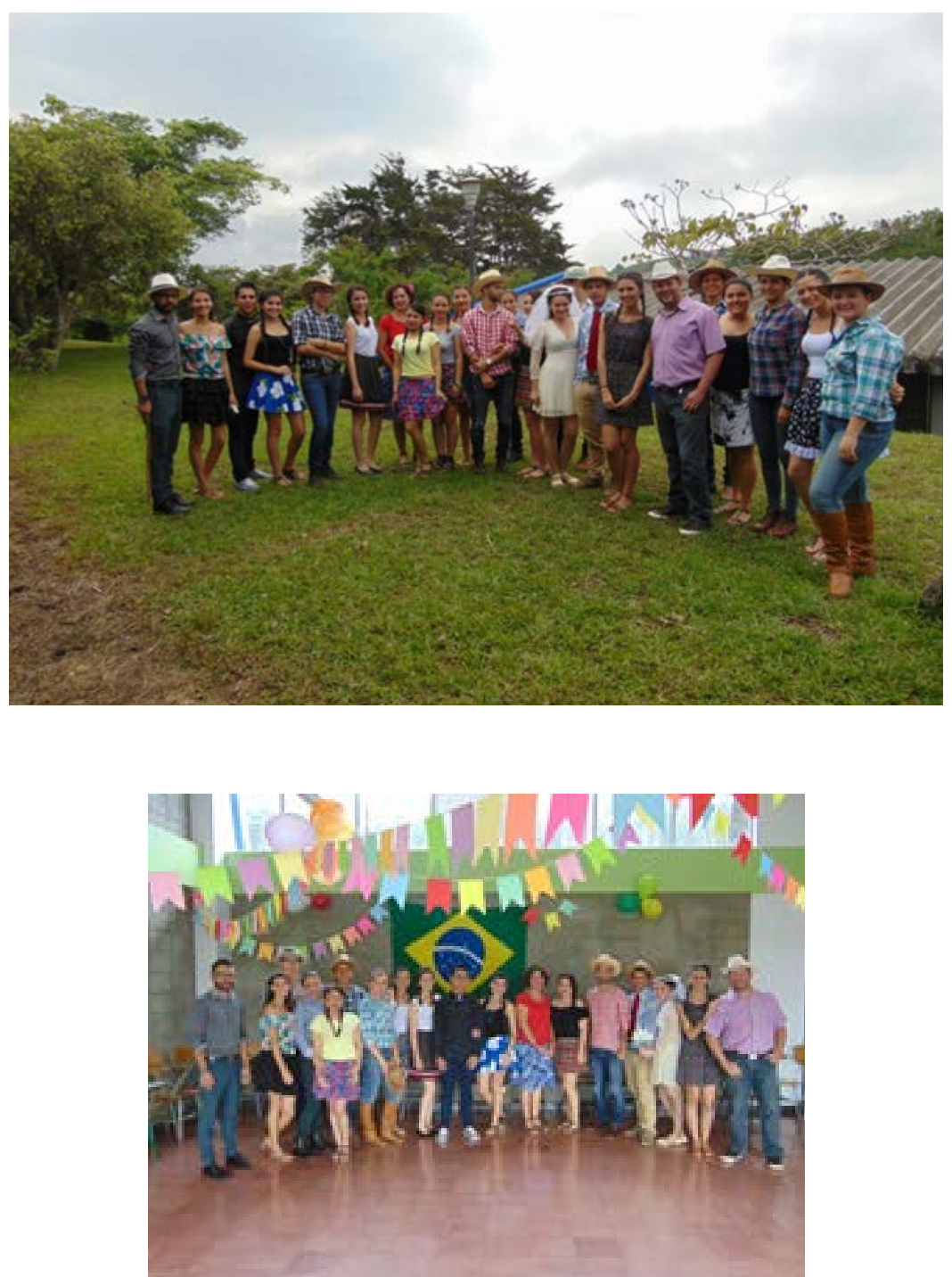